\title{
Gastrodia elata Blume protects against stress-induced gastric mucosal lesions in mice
}

\author{
SANG-MI AN ${ }^{1 *}$, CHUL-HONG PARK ${ }^{2 *}$, JIN-CHUL HEO ${ }^{1}$, JA-YOUNG PARK $^{3}$, SANG-UK WOO $^{3}$, JI-HYE SEO ${ }^{3}$, \\ MI-SOON LEE ${ }^{3}$, KANG-JIN CHO ${ }^{4}$, HYUN-SUK CHO ${ }^{4}$, HEUNG MOOK SHIN ${ }^{5}$ and SANG-HAN LEE ${ }^{1,2,3}$ \\ ${ }^{1}$ Food and Bio-Industry Research Institute, ${ }^{2}$ School of Life and Food Science, ${ }^{3}$ Department of Food Science and Technology, \\ Kyungpook National University, Daegu 702-701; ${ }^{4}$ National Institute of Agricultural Biotechnology, RDA, \\ Suwon 441-100; ${ }^{5}$ College of Oriental Medicine, Dongguk University, Kyungju 780-714, Korea
}

Received January 9, 2007; Accepted February 21, 2007

\begin{abstract}
Gastrodia elata Blume (GEB) is a traditional herbal plant that has been used in Asian countries for centuries as an anticonvulsant, analgesic, and also as a sedative for treating general paralysis, epilepsy, vertigo, and tetanus. Although numerous reports have addressed the effects of GEB against degenerative diseases, no previous study has examined the possible gastroprotective effects of GEB. Here, we examined the effects of pretreatment with GEB $(0.02 \mathrm{ml} / \mathrm{g}$, p.o.) in a mouse water immersion restraint (WIR) stressinduced gastric lesion model. Our results revealed that mice pretreated with GEB had significantly fewer gastric lesions than their respective controls. Moreover, GEB-treated mice showed significant decreases in serum and gastric nitric oxide (NO) levels to 50 and 28\%, respectively. To examine one possible mechanism underlying this effect, we used reverse transcription-polymerase chain reaction (RT-PCR) to examine NOS mRNA expression in gastric lesion tissues. Our results revealed that the mRNA expression of inducible nitric oxide synthase (iNOS) was reduced by $\sim 50 \%$ in GEB-pretreated mice versus the controls, whereas the mRNA expression levels of endothelial nitric oxide synthase (eNOS) and
\end{abstract}

Correspondence to: Professor Sang-Han Lee, School of Life and Food Science, Kyungpook National University, Daegu 702-701, Korea

E-mail: sang@knu.ac.kr

${ }^{*}$ Contributed equally

Abbreviations: GEB, Gastrodia elata Blume; WIR, water immersion restraint; RT-PCR, reverse transcription-polymerase chain reaction; iNOS, inducible nitric oxide synthase; eNOS, endothelial nitric oxide synthase; nNOS, neuronal nitric oxide synthase; cNOS, constitutive nitric oxide synthase; i.p., intraperitoneal; p.o., peroral

Key words: gastric lesion, water immersion restraint stress, inducible nitric oxide synthase, RT-PCR, Gastrodia elata Blume neuronal nitric oxide synthase (nNOS) remained unchanged. These findings collectively suggest that GEB significantly protects the gastric mucosa against WIR-induced gastric damage, at least in part by decreasing NO levels via suppression of iNOS mRNA expression.

\section{Introduction}

Acute gastric mucosal lesions represent a serious clinical problem worldwide. In an effort to facilitate the study of acute gastric damage, researchers have developed a number of gastric lesion animal models, including those induced by water immersion restraint (WIR) stress in rodents (1). This model has previously been used to examine various factors affecting the formation and healing of gastric mucosal lesions, including sulphydryls, endogenous prostaglandins, growth factors and polyamines (2). WIR stress-induced gastric lesions have also been used to examine the roles of apoptosis and gastric acid secretion in ulcerogenesis (3). In general, gastric lesions are disturbances in the gastric barrier function that normally protects the mucosa against deep damage by hydrogen ions and other noxious substances produced in the gastric lumen (4). One major component of gastric barrier function is gastric microcirculation; disturbance of gastric mucosal perfusion results in the formation of erosions and ulcers, such as those seen in experimental models of ischemic gastric lesions (5). Gastric blood flow is typically regulated by signaling molecules such as prostaglandins and nitric oxide (NO), the latter of which plays numerous roles in maintaining mucosal integrity (6). NO is primarily produced by nitric oxide synthase, which is generally divided into two classes: constitutive nitric oxide synthase (cNOS) and inducible nitric oxide synthase (iNOS). The cNOS isoforms include endothelial nitric oxide synthase (eNOS), which regulates vascular homeostasis in endothelial cells, platelets and mesangial renal cells (7), and neuronal nitric oxide synthase (nNOS), which produces NO to act as a neurotransmitter in the central and peripheral nervous system (8). The third major isoform, iNOS, is a calcium-independent enzyme located in macrophages, hepatocytes, smooth vascular muscles, neutrophils and endothelial cells (9). These NOS isoforms have been characterized in the gastrointestinal tract, and NO generated 
from cNOS and iNOS has been shown to play an important role in the formation of gastric lesions (10).

Numerous studies have investigated methods for treating and/or preventing gastric lesions with synthetic drugs (11). More recently, researchers have begun examining the possible usefulness of traditional Asian herbal remedies (12). One such traditional herbal agent, Gastrodia elata Blume (GEB), has been used in Asian countries for centuries as an anti-convulsant, analgesic and sedative against vertigo, general paralysis, and tetanus. Previous in vitro and in vivo studies have confirmed that constituents from GEB have anticonvulsive activity (13-15), but no prior study has investigated whether GEB has gastroprotective effects.

Here, we examined whether GEB has gastroprotective effects against WIR stress-induced gastric lesions in mice, and we further tested whether the identified gastroprotection acted via changes in NO content and NOS mRNA expression.

\section{Materials and methods}

Chemicals. Trizol ${ }^{\circledR}$ reagent was obtained from Invitrogen (Carlsbad, CA). L-arginine and diethyl ether were purchased from Junsei Chemicals (Tokyo, Japan). Sodium nitrate was obtained from Janssen Pharmaceutica (Mississauga, Ontario, Canada). Sodium chloride, phosphoric acid, formaldehyde, ethidium bromide (EtBr), sulfanilamide and $\mathrm{N}$-(1-naphthyl) ethylenediamine dihydrochloride (NED) were purchased from Sigma (St. Louis, MO). QA-Agarose was purchased from Qbiogene, Inc. (Irvine, CA). The Maxime RT-PCR PreMix kit was purchased from iNtRON Biotechnology (Sungnam, Korea). All other chemicals were of analytical grade.

Preparation of the GEB extract. Three-year-old rhizomes of GEB were obtained from Gastrodia Farm in YoungYang, KyoungBuk Province, Korea. The washed and chopped fresh GEB was deep-frozen at $-70^{\circ} \mathrm{C}$ until freeze-dried to get power. GEB was extracted with methanol and the methanol extract was re-suspended in $30 \%$ methanol. After centrifugation, the supernatants were dried in a rotary evaporator. The color of the fraction was dark brown.

Animals and care. Eight-week-old male BALB/c SPF mice, weighing between 22-25 g, were obtained from Samtaco (Suwon, Korea), and were fed a commercial diet (Samtaco, Korea) and water ad libitum. The animals were housed under a 12-h light/dark cycle at a temperature of $22 \pm 1^{\circ} \mathrm{C}$ and a humidity of $50 \pm 5 \%$. All animal care was carried out according to the in-house guidelines of the university, and animals were allowed to acclimate to the laboratory environment for at least 1 week prior to the experiments.

Induction of gastric mucosal lesions and experimental treatments. The WIR stress-induced gastric lesion mouse model was generated as described previously (1). The mice were randomly divided into control (no treatment), L-arginine $(300 \mathrm{mg} / \mathrm{kg})$ and GEB $(20 \mathrm{ml} / \mathrm{kg})$ groups $(\mathrm{n}=6$ mice per group, as described below). L-arginine was used as a positive control and comparative agent, since previous reports indicated that exogenously-administered L-arginine had
Table I. Effect of pretreatment with L-arginine and Gastrodia elata Blume on WIR stress-induced development of gastric mucosal lesions in mice.

Pretreatment

Ulcer index (points)

Control (i.p.)

$23.0 \pm 4.1$

Control (p.o.)

$23.3 \pm 7.8$

L-arginine (300 mg/kg, i.p.)

$8.0 \pm 5.5^{\mathrm{ab}}$

GEB (0.02 ml/g, p.o.)

$2.5 \pm 3.3^{\mathrm{ab}}$

Data are the mean $\pm \mathrm{SD}$ ( $\mathrm{n}=6$ animals per group). ${ }^{\mathrm{a}} \mathrm{P}<0.05$ compared with the i.p.-injected control group; ${ }^{b} \mathrm{P}<0.05$ compared with the p.o.-injected control group. The results were analyzed by one-way ANOVA followed by Dunnett's test.

protective effects against acute gastric mucosal lesions (16). Prior to injections, food was withheld for $24 \mathrm{~h}$, but the mice were allowed free access to water. The mice in the L-arginine treatment group $(n=6)$ each received one intraperitoneal (i.p.) injection of L-arginine $(300 \mathrm{mg} / \mathrm{kg})$ dissolved in isotonic saline; those in the GEB treatment group $(n=6)$ each received one peroral (p.o.) injection of GEB $(0.02 \mathrm{ml} / \mathrm{g})$; and those in the two respective control groups $(n=6)$ each received a single volume-matched i.p. or p.o. injection of isotonic saline. After the injections, the animals were returned to their cages for $1 \mathrm{~h}$ to allow drug absorption, and then placed in individual restraint cages and vertically immersed in a water bath (temperature held at $20-23^{\circ} \mathrm{C}$ ) to the level of the xyphoid process. The mice were not allowed access to food or drink during immersion. After a 6-h exposure to immersion stress, the mice were euthanized with diethyl ether and their stomachs were removed. Each stomach was cut open along the greater curvature, and the gastric mucosa was removed using a pair of small scissors. The gastric mucosa was carefully examined for lesions and/or linear breaks (erosions) at the glandular part of the mucosal surface. Blood was collected from the inferior vena cava of each mouse shortly after removal of the stomach, and serum samples were obtained by centrifugation.

Determination of ulcer index. Mucosal lesions were scored as previously reported (17). Briefly, 1 point was given for small round hemorrhagic erosions, 2 points when the length of the hemorrhagic erosion was $<1 \mathrm{~mm}, 3$ points when the length was 1-2 mm, 4 points when the length was $2-3 \mathrm{~mm}$, and 5 points when the length was $>4 \mathrm{~mm}$. This score was then doubled when the width of the erosion was $>1 \mathrm{~mm}$.

Measurement of NO production. The NO contents in the serum were measured via a slight modification of Griess assay (18). Briefly, the serum was added to a 96-well plate with activators (LPS $10 \mathrm{ng} /$ well), and GEB extract (final concentration $30 \mu \mathrm{g} / \mathrm{ml}$ ) was added. After $24 \mathrm{~h}$, the supernatant was collected $(100 \mu \mathrm{l})$ and an equal volume of Griess reagent ( $1 \%$ sulfanilamide, $0.1 \%$ naphthylethylene diamine dihydrochloride and 5\% phosphoric acid) was added and incubated at room temperature for $10 \mathrm{~min}$. The optical density of each sample was read at $550 \mathrm{~nm}$ by a microplate reader Victor3 


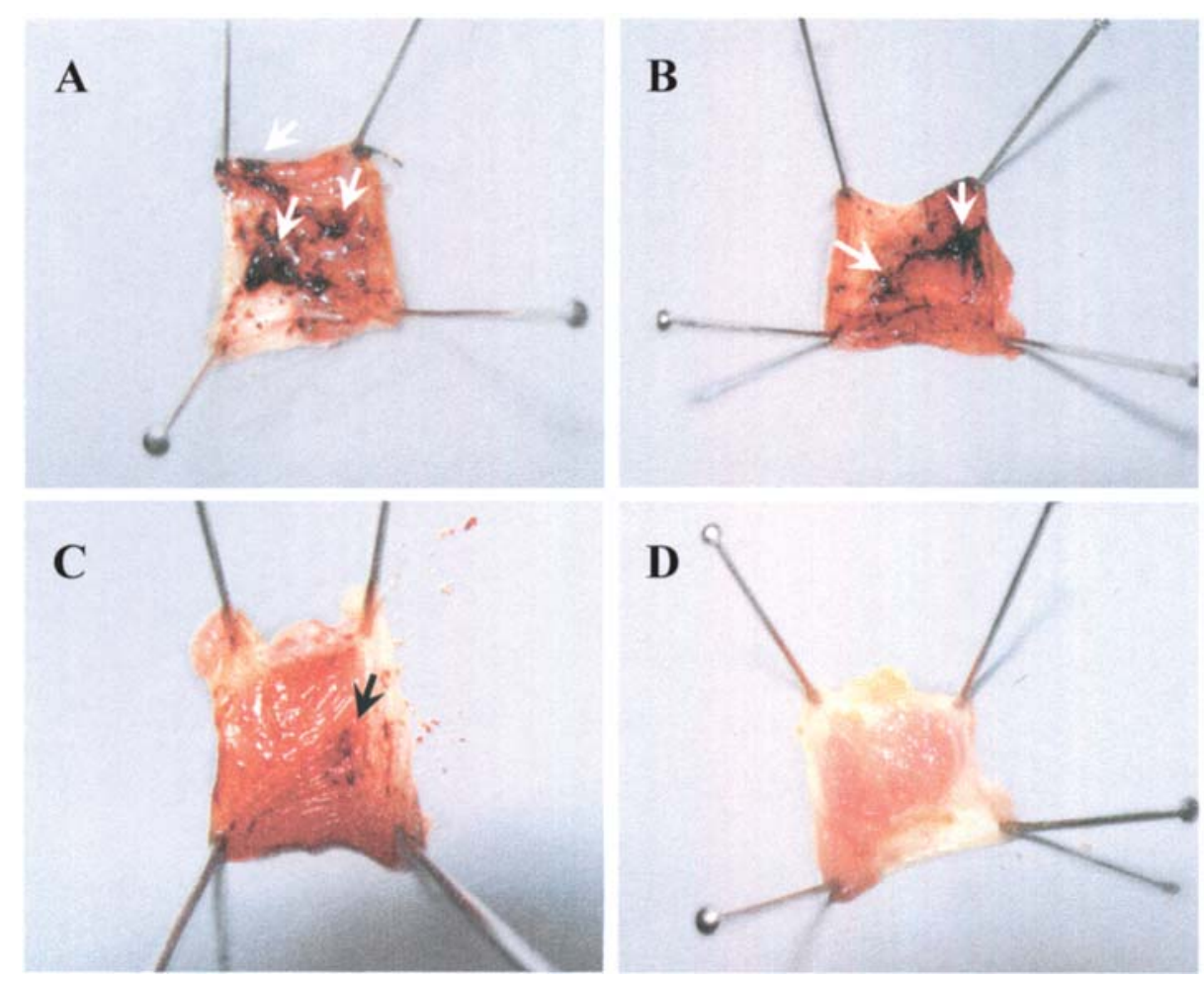

Figure 1. WIR stress-induced gastric mucosal lesions in mice. One hour prior to initiation of WIR stress, negative control mice received a single saline injection either i.p. (A) or p.o. (B); positive control mice received a single i.p. injection of L-arginine (300 mg/kg) (C); and experimental mice received a single p.o. injection of GEB $(0.02 \mathrm{ml} / \mathrm{g})(\mathrm{D})$. After a 6-h exposure to WIR stress, mice were euthanized and their stomachs were examined for gastric lesions, which were visualized as either punctuate or linear forms (black and white arrows).

(Wallac, Turku, Finland). The calibration curve was prepared using sodium nitrite as a standard.

Reverse-transcription polymerase chain reaction analysis of iNOS mRNA expression. Frozen gastric tissue $(\sim 100 \mathrm{mg})$ was homogenized in $1 \mathrm{ml}$ Trizol reagent, and total RNA was prepared as described elsewhere (19). The total RNA was quantified by spectrophotometry at $260 \mathrm{~nm}$ (Victor3 spectrophotometer; Perkin-Elmer, Wellesley, MA) and the RNA quality was examined by $1 \%$ formaldehyde-agarose gel electrophoresis and EtBr staining. The RNA samples were then stored at $-80^{\circ} \mathrm{C}$ until use. Single-step RT-PCR was performed using the Maxime RT-PCR PreMix, along with specific primer sets. These primers were designed using the Primer3 software (Whitehead Institute, MIT Center for Genome Research, Cambridge, MA) to analyze sequences deposited in the NCBI GenBank database. The primers, which were synthesized by Bioneer Co. (Daejeon, Korea), are shown in Table II. Briefly, first-strand cDNA was reversetranscribed from $500 \mathrm{ng}$ of total RNA at $45^{\circ} \mathrm{C}$ for $30 \mathrm{~min}$, and the samples were denatured for $5 \mathrm{~min}$ at $95^{\circ} \mathrm{C}$. PCR amplification was performed with 32 cycles (eNOS, nNOS and iNOS) or 27 cycles (GAPDH) of $45 \mathrm{sec}$ at $95^{\circ} \mathrm{C}, 45 \mathrm{sec}$ at $54^{\circ} \mathrm{C}$ for eNOS, $55^{\circ} \mathrm{C}$ for nNOS, $53^{\circ} \mathrm{C}$ for iNOS or $54^{\circ} \mathrm{C}$ for GAPDH, and $60 \mathrm{sec}$ at $72^{\circ} \mathrm{C}$. Following amplification, $20 \mu 1$ of each RT-PCR product was resolved by $1.5 \%$ agarose gel electrophoresis and visualized by EtBr staining. The location of the predicted product was confirmed by comparison to a 1-kb DNA ladder (Solgent, Daejeon, Korea). For semi-quantitative analysis, the relative amounts of cDNA in each matched set were normalized with regard to GAPDH expression using the Molecular Imager Gel Doc XR system and the Quantity One 1-D analysis software (Bio-Rad, Philadelphia, PA).

Statistical analysis. All data were presented as means \pm standard deviation (SD). Statistical analyses were performed with one-way analysis of variance (ANOVA), followed by Dunnett's test. P-values $<0.05$ were considered statistically significant.

\section{Results}

The effect of GEB on WIR stress-induced gastric mucosal lesions. One hour prior to initiation of WIR-induced stress, negative control mice received a single saline injection either i.p. or p.o., whereas positive control mice received a single i.p. injection of L-arginine at a concentration of $300 \mathrm{mg} / \mathrm{kg}$. Experimental mice received a single p.o. injection of GEB $(0.02 \mathrm{ml} / \mathrm{g})$. After a 6 -h exposure to WIR-induced stress, all mice were euthanized and their stomachs were examined for gastric lesions, which were visualized as either punctuate or linear forms. In samples from both control groups (i.p.- and p.o.-injected), we observed numerous lesions (Fig. 1A and B), most often 1-2 $\mathrm{mm}$ in size. In contrast, samples from the L-arginine-treated mice showed very few lesions as shown in Fig. 1. While control groups showed large-size blood-clotting clumps (Fig. 1A and B), in the positive control only mediumsize clumps with minor numerous lesions were detected, which was not significant compared to the negative controls. 
Table II. Oligonucleotide primers used for PCR reactions.

\begin{tabular}{llll}
\hline Name & Sequence of forward (F) or reverse (R) primer & Length (bp) \\
\hline eNOS & 5'-TACGCACCCAGAGCTTTTCT-3' & F & 307 \\
& 5'-GCAGGATGCCCTAACTACCA-3' & R & F \\
nNOS & 5'-CCATCAGCTCCTCTCCAGAC-3' & R & 511 \\
& 5'-ATATGGCCTCCTTGCTCCTT-3' & F & 305 \\
iNOS & 5'-AGACCTCAACAGAGCCCTCA-3' & R & 371 \\
& 5'-GCAGCCTCTTGTCTTTGACC-3' & F & R \\
\hline
\end{tabular}

A

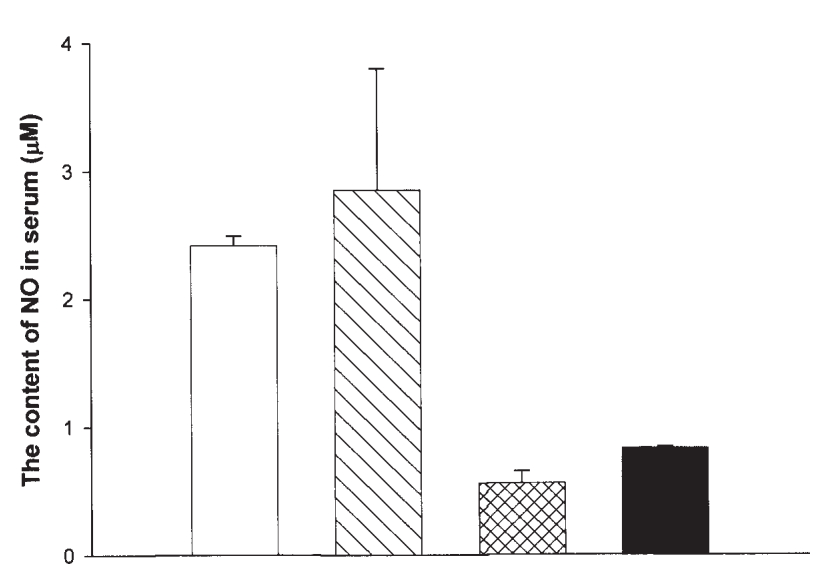

B

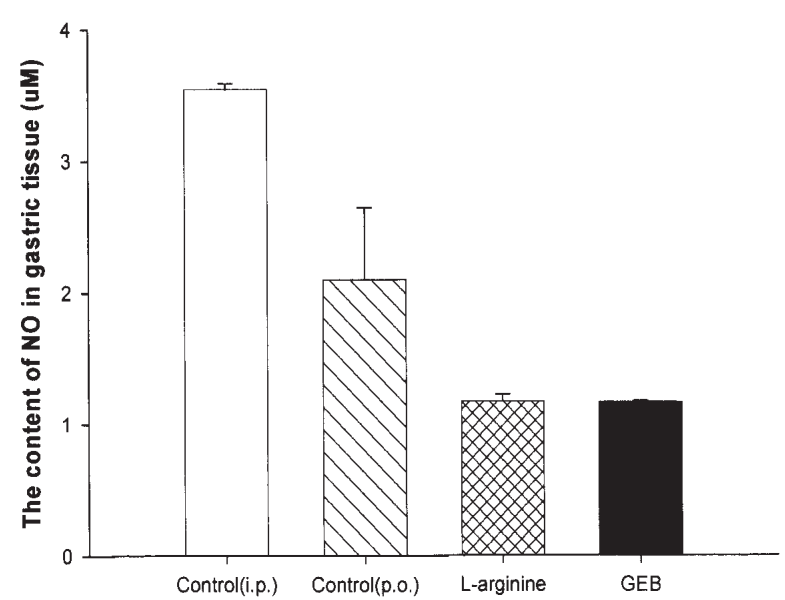

Figure 2. NO contents in serum and gastric tissue samples from mice exposed to WIR stress. One hour prior to initiation of WIR stress, negative control mice received a single saline injection either i.p. (white bar) or p.o. (bar with one set of diagonal lines); positive control mice received a single i.p. injection of L-arginine (300 mg/kg) (bar with a double set of diagonal lines); and experimental mice received a single p.o. injection of GEB (0.02 ml/g) (black bar). The presented data are the mean $\pm \mathrm{SD}$ of triplicate experiments. The results were analyzed by one-way ANOVA, followed by Dunnett's test. * $\mathrm{P}<0.05$ compared with the i.p. controls; ${ }^{\dagger} \mathrm{P}<0.05$ compared with the p.o. controls.

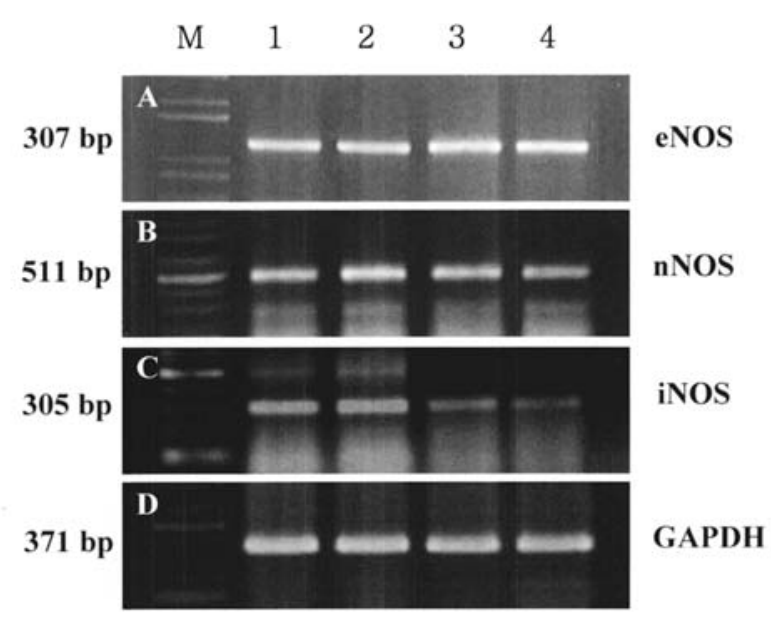

Figure 3. The mRNA expression levels of nitric oxide synthases in gastric tissue samples of mice exposed to WIR stress. mRNA expression levels of eNOS (A), nNOS (B), iNOS (C) and GAPDH (D) are shown. Lane M, PCR size marker; lane 1, i.p.-injected control group; lane 2, p.o.-injected control group; lane 3, L-arginine (300 $\mathrm{mg} / \mathrm{kg}$, i.p.)-treated positive control group; lane 4, GEB (0.02 ml/g, p.o.)-treated experimental group.
In Fig. 1D, GEB-treated mice showed no small-size clumps as well as large-size lesions. By scoring mucosal lesions with a slight modification of Nie et al (17), we compared the ulcer index as shown in Table I. The ulcer indices of the negative controls were $23.0 \pm 4.1$ and $23.3 \pm 7.8$, respectively, whereas that of the positive control was 8.0 5 5.5. Collectively, these findings indicate that GEB protects against WIR stressinduced gastric lesions in mice.

Changes in NO content. To begin addressing the mechanisms underlying the gastroprotective effects of GEB, we examined the NO content in serum and gastric tissue samples from the various groups of mice. As shown in Fig. 2, both L-arginineand GEB-pretreated mice showed significant decreases in serum and gastric tissue NO levels with respect to their controls (51 and 50\%, respectively, and 50 and $28 \%$, respectively; all $\mathrm{P}<0.05)$. These findings suggest that GEB treatment decreases NO levels in serum and gastric tissues, and further indicates that a similar NO level decrease is seen in mice treated with the known gastroprotective agent, L-arginine. 
A

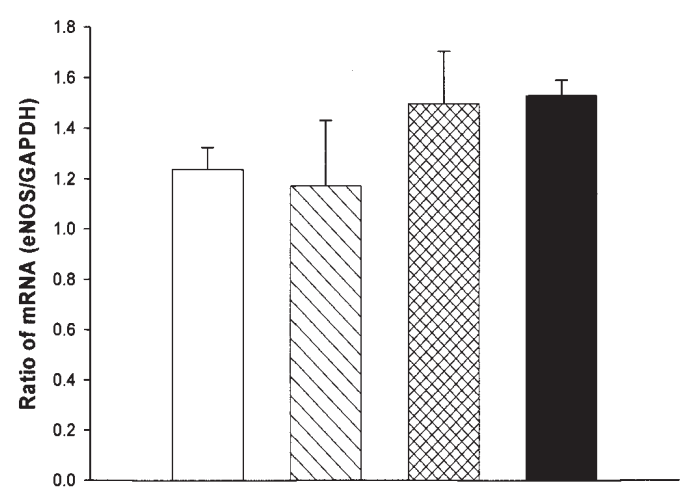

B

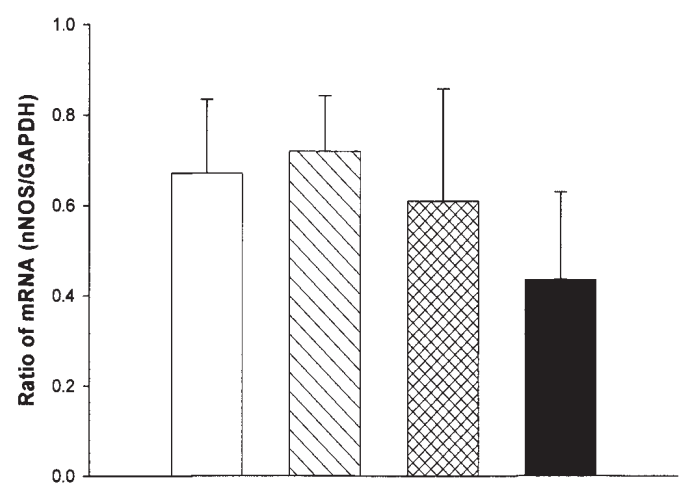

\section{C}

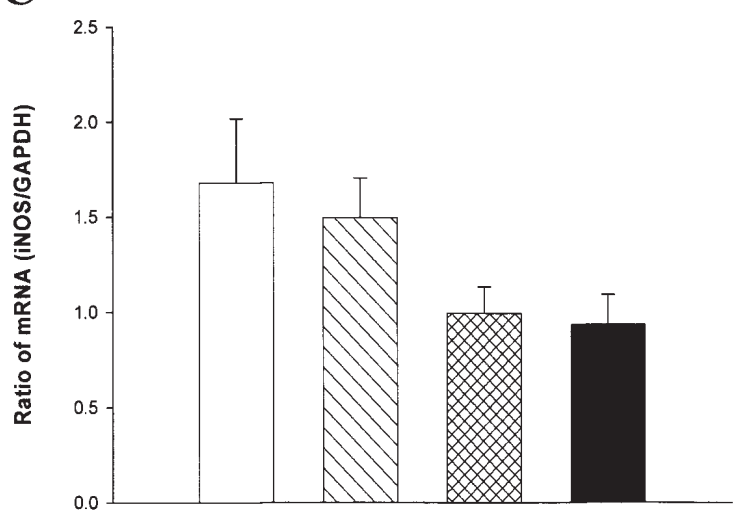

Figure 4. Comparison of nitric oxide synthase mRNA expression levels. The mRNA expression levels of eNOS (A), nNOS (B) and iNOS (C) mRNA were normalized versus that of GADPH, using Quantity One version 4.6.1 (Bio-Rad, Philadelphia, PA). One hour prior to initiation of WIR stress, negative control mice received a single saline injection either i.p. (white bar) or p.o. (bar with one set of diagonal lines); positive control mice received a single i.p. injection of L-arginine $(300 \mathrm{mg} / \mathrm{kg}$ ) (bar with a double set of diagonal lines); and experimental mice received a single p.o. injection of GEB (0.02 ml/g) (black bar). The presented data are the mean \pm SD from three mice. The results were analyzed by one-way ANOVA, followed by Dunnett's test. ${ }^{*} \mathrm{P}<0.05$ compared with the i.p. controls; ${ }^{\dagger} \mathrm{P}<0.05$ compared with the p.o. controls.

Expression profiles of eNOS, nNOS and iNOS mRNA. To test whether the observed changes in serum and gastric tissue NO levels were due to changes in the expression levels of eNOS, nNOS and iNOS, we used RT-PCR to examine the mRNA transcript levels of the genes encoding these enzymes. As shown in Figs. 3 and 4, the 305-bp product corresponding to the iNOS cDNA was markedly decreased in gastric tissues from WIR stress-induced lesions, whereas the levels of the 307-bp eNOS and 511-bp nNOS fragments were similar in all tested samples, regardless of treatment.

\section{Discussion}

We herein report for the first time that pretreatment with the traditional herbal plant, Gastrodia elata Blume (GEB), protects against WIR stress-induced gastric mucosal lesions in mice (Fig. 1 and Table I). This finding notably suggests that GEB can be applied for ulcer remedies.

We further show for the first time that the gastroprotective effects of GEB appear to involve suppression of nitric oxide levels via decreased mRNA expression of iNOS. Previous studies have shown that WIR-induced gastric mucosal lesions are associated with increased gastric acid production, accelerated gastric peristalsis, microcirculation disturbances in the gastric mucosa, decreased prostaglandin levels, low turnover of gastric mucous cells, and NO-mediated changes in the homeostatic functions of the gastric mucosa (20-22). Of these mechanisms, NO-mediated regulation is particularly important, as it is involved in host defense and inflammatory responses (23), and also plays a critical role in gastric mucosal protection against injury induced by pressure, ethanol, stress and/or endotoxins (24). NOS activity is particularly high in gastric tissue (25), where NO helps maintain the integrity of the gastric epithelium (26), regulates gastric mucosal blood flow (27), and stimulates gastric mucus secretion and synthesis (25). The NO donor, glyceryl trinitrate, and the NOS substrate, L-arginine, have been shown to accelerate gastric ulcer healing in rats by increasing angiogenesis in the stomach (16). Consistent with this, inhibition of NOS activity was shown to attenuate the stimulatory effects of NO on mucus synthesis and secretion, inhibit angiogenesis, and impair ulcer healing $(10,28)$.

In the present study, we showed that GEB-pretreated mice exposed to WIR stress had lower serum and gastric tissue NO contents than control stressed mice (Fig. 2). Similar results were obtained from L-arginine-pretreated mice, which 
were used as a positive control based on a previous report that L-arginine pretreatment prevented the development of stress-induced gastric lesions (16). To test one possible mechanism underlying the observed decrease in NO content, we examined the expression levels of various NOS mRNAs. Our results revealed that the gastric mucosal expression of iNOS mRNA was significantly lower in GEB- and L-argininepretreated mice versus controls, whereas no such differences were observed in eNOS and nNOS mRNA expression levels (Figs. 3 and 4). These findings collectively suggest that the protective effects of $\mathrm{NO}$ against stress-induced gastric lesions in mice may be due, at least in part, to suppression of NO signaling via decreased iNOS mRNA expression by GEB.

Notably, previous studies have indicated the importance of cNOS in maintaining healthy gastric mucosa. Decreased cNOS activity has been associated with gastric erosion, while increased cNOS mRNA expression, activity and immunoreactivity has been seen in healing gastric mucosa, particularly in newly-formed vessels and neurons (29). Consistent with the notion that cNOS is a critical factor in gastric tissue repair, cigarette smoking-induced reductions in mucosal NOS activity have been associated with decreased gastric blood flow and suppression of angiogenesis at ulcer margins (10). However, we did not observe altered cNOS (eNOS and nNOS) mRNA expression in GEB- or L-arginine-pretreated mice exposed to WIR-induced stress. Instead, we observed changes in the mRNA expression levels of iNOS, suggesting that this isoform may be involved in the active mechanism of GEB-induced gastroprevention.

Large amounts of iNOS-generated NO have been implicated in gastric tissue injury during inflammatory reactions (30), and high iNOS expression and activity have been associated with severe inflammation in ulcerative mucosal tissues (31). Studies have shown that iNOS is usually induced under oxidative conditions, wherein high levels of $\mathrm{NO}$ can react with the superoxide anion $\left(\mathrm{O}_{2}^{-}\right)$, thus leading to peroxynitrite (ONOO-) formation, protein tyrosine nitration, hydroxyl radical production, cell toxicity and tissue damage $(31,32)$. In the present study, we observed high-levels of iNOS mRNA expression in the gastric mucosal lesions of control mice, but significantly lower levels in GEB-pretreated mice, suggesting that GEB might decrease NO production by inhibiting iNOS expression in WIR-induced gastric mucosal lesions. This may then prevent the abundant release of damaging NO, leading to gastroprotection.

In summary, we herein show for the first time that exogenously administered GEB protects against the development of WIR stress-induced gastric mucosal lesions in mice, and that this effect may be due, at least in part, to decreased iNOS mRNA expression and subsequent decreases in damaging NO levels. Although future studies will be needed to clarify the detailed mechanisms of this protective effect, these novel findings represent a new mode of action for GEB and may suggest that this traditional herbal plant or its extract could be developed for future use in ulcer prevention.

\section{Acknowledgements}

This study was partly supported by a grant (no. 20050301034-474-006) from the BioGreen 21 Program, RDA, Korea.
Mi-Soon Lee was supported by a scholarship from the AgroBiotechnology Education Center, Kyungpook National University, Daegu, Korea. This work was also supported in part by a grant of Oriental Medicine R\&D Project, Ministry of Health \& Welfare, Korea (HMP-B050042) on NOS assay (H.M.S.).

\section{References}

1. Takagi KY, Kayuya Y and Watanabe K: Studies on drugs for peptic ulcer. A reliable method for producing stress ulcers in rats. Chem Pharm Bull 12: 465-472, 1964.

2. Brzozowski T, Konturek SJ, Kwiecien S, Pajdo R, Drozdowicz D, Sliwowski Z and Muramatsu M: SV-480, a novel synthetic flavonoid derivative of sophoradin, with potent gastroprotective and ulcer healing activity. J Physiol Pharmacol 46: 83-98, 1998 .

3. Kwiecieñ S, Brzozowski T, Konturek PC, Konturek SJ, Pawlik M, Pajdo R, Drozdowicz D, Ptak A and Hahn EG: Effect of central and peripheral actions of histamine and its metabolite $\mathrm{N}$-alpha methyl histamine on gastric secretion and acute gastric lesions. J Physiol Pharmacol 52: 625-638, 2001.

4. Konturek PC: Physiological, immunohistochemical and molecular aspects of gastric adaptation to stress, aspirin and to H. pylori-derived gastrotoxins. J Physiol Pharmacol 48: 3-42, 1997.

5. Brzozowski T, Konturek PC, Pajdo R, Kwiecien S, Ptak A, Sliwowski Z, Drozdowicz D, Pawlik M, Konturek SJ and Hahn EG: Brain-gut axis in gastroprotection by leptin and cholecystokinin against ischemia - reperfusion induced gastric lesions. J Physiol Pharmacol 52: 583-602, 2001.

6. Pawlik M, Ptak A, Pajdo R, Konturek PC, Brzozowski T and Konturek SJ: Sensory nerves and calcitonin gene related peptide in the effect of ischemic preconditioning on acute and chronic gastric lesions induced by ischemia-reperfusion. J Physiol Pharmacol 52: 569-581, 2001.

7. Nishida K, Harrison DG, Navas JP, Fisher AA, Dockery SP, Uematsu M, Nerem RM, Alexander RW and Murphy TJ: Molecular cloning and characterization of the constitutive bovine aortic endothelial cell nitric oxide synthase. J Clin Invest 90: 2092-2096, 1992.

8. Moncada S, Higgs EA and Furchgott R: International union of pharmacology nomenclature in nitric oxide research. Pharmacol Rev 49: 137-142, 1997.

9. Anggard E: Nitric oxide: mediator, murderer, and medicine. Lancet 343: 1199-1206, 1994.

10. Ma L, Chow JY and Cho CH: Cigarette smoking delays ulcer healing: Role of constitutive nitric oxide synthase in rat stomach. Am J Physiol 276: 238-248, 1999.

11. La Vecchia C and Tavani A: A review of epidemiological studies on cancer in relation to the use of anti-ulcer drugs. Eur $\mathbf{J}$ Cancer Prev 11: 117-123, 2002.

12. Schmeda-Hirschmann G and Yesilada E: Traditional medicine and gastroprotective crude drugs. J Ethnopharmacol 100: 61-66, 2005

13. Huh K, Yi SJ, Shin US and Park JM: Effect of the ether fraction of Gastrodia elata methanol extract on the pentylenetetrazoleinduced seizures. J Appl Pharmacol 3: 199-204, 1995.

14. Hsieh CL, Tang NY, Chiang SY, Hsieh CT and Lin JG: Anticonvulsive and free radical scavenging actions of two herbs, Uncaria rhynchophylla (MIQ) Jack and Gastrodia elata B1., in kainic acid-treated rats. Life Sci 65: 2071-2082, 1999.

15. Kim HJ, Moon KD, Oh SY, Kim SP and Lee SR: Ether fraction of methanol extracts of Gastrodia elata, a traditional medicinal herb, protects against kainic acid-induced neuronal damage in the mouse hippocampus. Neurosci Lett 314: 65-68, 2001.

16. Brzozowski T, Konturek SJ, Sliwowski Z, Drozdowicz D, Zaczek M and Kedra D: Role of L-arginine, a substrate for nitric oxide-synthase, in gastroprotection and ulcer healing. J Gastroenterol 32: 442-452, 1997.

17. Nie SN, Qian XM, Wu XH, Yang SY, Tang WJ, Xu BH, Huang F, Lin X, Sun DY, Sun HC and Li ZS: Role of TFF in healing of stress-induced gastric lesions. World J Gastroenterol 9: 1772-1776, 2003.

18. Dirsch VM, Stuppner H and Vollmar AM: The Griess assay: suitable for a bio-guided fractionation of anti-inflammatory plant extracts? Planta Med 64: 423-426, 1998. 
19. Roos-van Groningen MC, Eikmans M, Baelde HJ, de Heer E and Bruijn JA: Improvement of extraction and processing of RNA from renal biopsies. Kidney Int 65: 97-105, 2004.

20. Kitagawa H, Fujiwara M and Osumi Y: Effects of waterimmersion stress on gastric secretion and mucosal blood flow in rats. Gastroenterology 77: 298-302, 1979.

21. Garrick T, Leung FW, Buack S, Hirabayashi K and Guth PH: Gastric motility is stimulated but overall blood flow is unaffected during cold restraint in the rat. Gastroenterology 91: 141-148, 1986.

22. Lamarque D and Whittle BJ: Involvement of superoxide and xanthine oxidase in neutrophil-independent rat gastric damage induced by NO donors. Br J Pharmacol 116: 1843-1848, 1995.

23. Calatayud S, Barrachina D and Esplugues JV: Nitric oxide: relation to integrity, injury, and healing of the gastric mucosa. Microsc Res Tech 53: 325-335, 2001.

24. Nishida K, Ohta Y and Ishiguro I: Role of gastric mucosal constitutive and inducible nitric oxide synthases in the development of stress-induced gastric mucosal lesions in rats. Biochem Biophys Res Commun 236: 275-279, 1997.

25. Brown JF, Hanson PJ and Whittle BJ: Nitric oxide donors increase mucus gel thickness in rat stomach. Eur J Pharmacol 223: 103-104, 1992.

26. Whittle BJ, Lopez-Belmonte J and Moncada S: Regulation of gastric mucosal integrity by endogenous nitric oxide: interactions with prostanoids and sensory neuropeptides in the rat. Br J Pharmacol 99: 607-611, 1990.
27. Pique JM, Esplugues JV and Whittle BJ: Endogenous nitric oxide as a mediator of gastric mucosal vasodilation during acid secretion. Gastroenterology 102: 168-174, 1992.

28. Konturek SJ, Brzozowski T, Majka J, Pytko-Polonczyk J and Stachura J: Inhibition of nitric oxide synthase delays healing of chronic gastric ulcers. Eur J Pharmacol 239: 215-217, 1993.

29. Brzozowski T, Konturek PC, Konturek SJ, Pajdo R, Drozdowicz D, Kwiecien S and Hahn EG: Acceleration of ulcer healing by cholecystokinin (CCK): role of CCK-A receptors, somatostatin, nitric oxide and sensory nerves. Regul Pept 82: 19-33, 1999.

30. Barrachina MD, Panes J and Esplugues JV: Role of nitric oxide in gastrointestinal inflammatory and ulcerative diseases: Perspective for drugs development. Curr Pharm Design 7: 3148,2001

31. Kankuri E, Vaali K, Knowles RG, Lahde M, Korpela R, Vapaatalo $\mathrm{H}$ and Moilanen E: Suppression of acute experimental colitis by a highly selective inducible nitric-oxide synthase inhibitor, N-[3-(aminomethyl)benzyl]acetamidine. J Pharmacol Exp Ther 298: 1128-1132, 2001.

32. Ding HL, Zhu HF, Dong JW, Zhu WZ, Yang WW, Yang HT and Zhou $\mathrm{ZN}$ : Inducible nitric oxide synthase contributes to intermittent hypoxia against ischemia/reperfusion injury. Acta Pharmacol Sin 26: 315-322, 2005. 